\title{
Holographic art with recording in three-dimensional media on the basis of Lippman photographic plates
}

\begin{abstract}
The paper discusses the properties of holographic materials together with their technologies as applied to three-dimensional recording mainly for artistic purposes. Also some attention is paid to the mechanisms of interaction of laser light and matter due to different types of exposures by using different types of lasers. Finally, the difficulties in the reproduction techniques are mentioned.
\end{abstract}

The hologram technique initially proposed for application to a specific technical problem [1] in recent years has found wider and wider use in the development of a new kind of art. The strange holographic pictures creating the full illusion of objects depicted are shown more and more frequently at various exhibitions, museums, private collections, and so on. The earliest idea of the possibility to utilize holography in this way was promoted in 1962 [2] in connection with the so-called holographic technique with recording in three-dimensional media. This idea was confirmed by the experiments carried out with the improved technology of Lippman colour photography [3-5].

The first hologram reconstructing three-dimensional image of a natural object was obtained in 1964 using the holographic method with recording in two-dimensional media [6]. This experiment is known as a turning point in the development of holography. The circumstances of publishing the experimental results in question seem to indicate that of all applications of holography the artistic holography is most interesting for the public in large.

Basically the technique of obtaining artistic holograms has not changed much as compared to the earlier works $[3,4,6]$. In a number of cases such holograms are recorded in! the passing beams, thus using the technique of registration in two dimensional media. In this case the reconstruction is accomplished with the help of monochromatic laser or mercury arc lamp radiation.

The recording in the opposite beams, i.e. the holography in three-dimensional media is also widely employed for the purposes of artistic holography. The main feature of the three-dimensional hologram

*) Academie of Ssience USSR, Institute of Optics, Leningrad, USSR. is the ability to separate a definite monochromatic component from the reconstructing radiation. Accordingly such a hologram can be reconstructed with an ordinary incandescent lamp. This property is rather opportune for practical purposes.

The recording and the chemical treatment of three-dimensional holograms is mainly carried out with the help of the photographic plates and developers which were worked out by Lippman and other investigators of that period (see e.g. [7]). However, both the plates and the methods of their chemical treatment have undergone considerable changes which resulted in an essential improvement in the quality of the image reconstructed. We shall discuss below the results of the development of artistic holography of this type in more detail.

As the whole volume of photographic material does take part in the reconstruction of a three-dimensional hologram, the quality of the reconstructed image in this case is especially dependent on the properties of the photographic plates used. The main ways of improving Lippman plates, since they first appeared till today, have been the search of methods to suppress the growth of haloid silver grains at the stage of emulsions synthesis, and the search of hypersensitizators increasing the sensitivity of these photographic plates $t^{o}$ the maximum.

The methods to reduce the size of haloid silver orystals are especially important.

In the emulsion used for obtaining the first three-dimensional holograms the growth of emulsion grains was slowed down due to the excess concentration of $\mathrm{KBr}$ [4]. In this way the emulsion containing haloid silver crystals of the order of $300 \AA$ in size has been obtained. The initial sensitivity of such emulsion was very low. It was substantially raised after the hypersensitization in a solution of triethanolamine (TEA). 
This method of hypersensitization of Lippman photographic plates proved to be highly effective and is being widely used now. Diffraction efficiency of the holograms on such photographic plates came to about $5 \%$.

The next step to improve the emulsion in question was the development of the so-called "Valenta" layer [8]. In this case, due to the introduction of instantaneous emulsification at a low temperature and other measures, the size of silver bromide grains has been reduced as early as at the emulsification stage. Reduction of grain size, as well as higher concentration of silver in the emulsion, allowed to increase the diffractional efficiency of holograms to the value of $20-24 \%$ quite acceptable for practical purposes. In plate treatment a special pyrogallic developer was employed [9]. The energy required for the recording of a hologram was of the order of $20-30 \cdot 10^{-3} \mathrm{~J} / \mathrm{cm}^{2}$ [10].

Using the experience in obtaining holograms on "Valenta" layers, Dr. R. R. Protas, the chief author of the initial emulsion mentioned above [4], succeeded in creating highly efficient and technologically effective Lippman photographic plates LOI-2 [11].

In this particular case the growth of haloid silver crystals was further slowed down due to the increasing number of growth centres and also due to the introduction of special growth inhibitors. Chemical treatment of LOI-2 photographic plates is accomplished in the GP-2 developer, worked out specially for such plates [12].

The sensitivity of these plates under condition of pretreatment in TEA amounts to $0.4 \cdot 10^{-3} \mathrm{~J} / \mathrm{cm}^{2}$. Diffractional efficiency of three-dimensional reflection holograms, recorded on LOI-2 photographic plates reaches quite a high value of $50-55 \%$. Such plates have been manufactured in factory conditions for quite a long time.

The best available home-made, though rather complicated in technology, Lippman photographic plates are PE-I photographic plates worked out by prof. N. I. KIRILLOV [13, 14]. In this case the growth of haloid silver crystals is hampered due to the fact that in emulsification process a highly diluted solution is used, and the concentration of emulsion is achieved by the method of gradual freezing-out and thawing-out. This method led to emulsion containing haloid silver crystals, not exceeding $100 \AA$ in size [15]. The treatment of PE-I photographic plates is accomplished in a special methol phenidone hydroquinone developer $[16,17]$. The sensitivity of PE-I photographic plates amounts to about $0.05 \cdot 10^{-3} \mathrm{~J} / \mathrm{cm}^{2}$ provided that the plates are pre-treated in TEA [17]. Without such a pre- -treatment the sensitivity becomes about 10 times lower and thus approaches the sensitivity of LOI-2 photographic plates treated with TEA. Diffraction efficiency of the PE-I photographic plates exceeds $50 \%$ [18]. Until recently the PE-I photographic plates have been manufactured in small-lot experimental production.

One of the most important prospects of the artistic holography is the transition from recording holograms on photographic plates to recording on the film. Obviously this will be fully realised only after the possibility is found to record high quality holograms in the light of pulsing lasers; so far, as in this case, the rigid fixing of the photographic layer will be no longer necessary. At the present time three-dimensional holograms can be recorded on the special photographic film FP-GT [19]. This film is about twice as sensitive as LOI-2 photographic plates, but has somewhat lower diffraction efficiency of the order of $25 \%$. It is interesting to note that if the hologram is being recorded in opposite beams the triacetate base is the only suitable one, because laser possesses a strong double-beam refraction. One should also take into account that if a gas discharge laser is to be employed for hologram recording, the film, while in storage, must not be rolled up in a roll to eliminate its deformation during exposure. It is desirable that the film be cut at once into separate sheets and packed like photographic plates.

Apart from the above-mentioned photographic materials which have been quite widely employed for recording three-dimensional holograms or have been manufactured at an industrial scale, two experimental layers are worth mentioning, namely, the silver iodide-bromide emulsion somewhat resembling LOI-2 [20], and the sublimation layer representing a further development of the technique of synthetizing emulsions from diluted solutions [21]. The last emulsion is rather interesting due to the fact that the author concentrated it by way of sublimation, i.e. by evaporating water directly from ice. This emulsion is likely to contain haloid silver crystals of the smallest size. It is peculiar that in this case diffractional efficiency of holograms has not practically increased, whereas the sensitivity of photographic plates has considerably decreased. This experiment, however, was entirely of preliminary character. It would be premature to draw a final conclusion concerning the unsuitability of further decrease in the size of haloid silver grains.

Passing over to the methods of increasing the sensitivity of Lippman photographic plates is should be noted that for practical purposes, apart from triethanolamine treatment [4], only hypersensitization by 
heating was proposed $[22,23]$. This method leads to nearly as great increase in sensitivity as does the hypersensitization in TEA, the shelf life of photographic plates being considerably longer. It is to be noted that the hypersensitization methods mentioned get sensitivity reserves from the same source and, therefore, cannot supplement each other.

Some scantiness of practical achievements in the sphere of increasing the sensitivity of photographic plates was compensated by the scientific success. In a number of papers some details of the nature of the reverses of sensitivity of Lippman photographic plates were made evident enough. The most interesting results were obtained by the so-called holographic method of latent image investigation [24-27]. By this original method the interference picture of two plane waves is recorded upon a photographic plate without further development. The light scattered by this picture is registered simultaneously on this recording. In this particular case the light is being scattered by the latent image centres which are formed during the exposure. While measuring the scattered light intensity one can investigate the behaviour of latent image in time. The mentioned investigations have shown that a strong regression in sensitivity is characteristic of superfinely dispersed photographic emulsions. During a period of about tens of seconds the intensity of the latent image contrives to decrease many times. The presence of such anomalous regression is also confirmed by the experiments aimed at reducing the time between the exposure and development [28]. It turned out that in this manner the light-sensitivity of Kodak 649F photographic plates can be increased 25 times. Most likely, the same fact is indirectly confirmed by a considerable decrease in light-sensitivity of the emulsion obtained by sublimation method [21]. In all probability, when haloid silver grains are reduced in size below a certain limit (judging by PE-I emulsions this limit lies in the region of $100 \AA$ ) the duration of their memory rapidly reduces.

We now turn our attention to the problems of interaction of the light and a developed hologram. At present one may take it as a proven fact that after a strongly exposed Lippman photographic plate is developed a colloid silver is formed in an emulsions layer. This means that billions of minute compact grains, well reflecting the light, appeare in the volume of the layers. With lower exposures silver exists in the same form as on the ordinary photographic plates [29]. To obtain a hologram of maximum diffraction efficiency it is to be exposed up to the exposures corresponding to the beginning of the colloid silver region [30]. Most likely, this is due to the fact that with shorter exposures silver reflects light badly, and with longer exposures the structure of layers printed into the hologram is washed away.

The modulation mechanism of radiation from a three-dimensional hologram registered on a Lippman photographic plate is conveniently interpreted from the standpoint that the presence of silver particles in the emulsion layer does change the effective refraction index of the layer [31]. The anomalous values of the refractive index of the developed Lippman plate structure were actually discovered in the experiment [32].

The estimation of the value of the light flux reflected by three-dimensional holograms of this type is complicated due to the fact that thanks to the harmonic nature of standing wave distribution in depth one and the same hologram has layers characterized by different exposure. In accordance with that, both small and large particles of colloid silver are represented in the volume of a hologram. There are two diametrically opposite viewpoints on the problem of what particular particles reflect the maximum amount of light. There are arguments for the view that the main role in the formation of the image is played by the light scattered on large-sized particles $[33,34]$. There are arguments for the opposite viewpoint as well [32].

As far as the radiation sources used in the registration of the three-dimensional artistic holograms are concerned it should be noted that at present the most suitable for the purpose are helium-neon lasers with cold cathode. Argon and krypton lasers, though posses a considerably higher power, are less handy as they require water colling. Among other effects such a cooling is sometimes a source of vibrations due to water pulsations in the water supply and feed pipes.

Pulsed lasers are, no doubt, the most perspective radiation sources for registration of artistic holograms. While employing such lasers there is no necessity to have bulky vibration-proof installations, registration of any objects becomes possible, including portraits, photographic films being employed as a photographic material. Pulsed lasers, however, are not sufficiently stable as yet, besides some complications have risen here in providing the suitable photographic materials. It appeared, for example, that registration of holograms with diffraction efficiency exceeding $10 \%$ is impossible if normal photographic plates and a mono-pulsed laser are employed. At the same time a longer pulse in free generation mode makes it possible to achieve $30 \%$ efficiency in hologram recording [35].

At present no special studies concerning the optimum choice of reconstructing source are available. 
It is known from the practice that the lamps used for this purpose are either mercury-arc lamps or incandescent lamps whose luminescence body is enlarged by means of optics up to the size sufficient to keep the reconstructing beam divergence within $30^{\prime}$. The sources of this type are relatively inexpensive and easy to handle, but their radiation is not sufficiently directive. Since this does cause washing away of the remote details of the image reconstructed, one should expect that in the near future the artistic holography will be restricted to the scenes of no more than tens of centimeters in depth. For the majority of art pices and portraits such a distance is sufficient.

The problem of colour reproduction is one of the most vital for the whole field in question. In spite of a number of successful studies (see e.g. [36]) the solution of the problem is still long to come to. To some extent this drawback of present-day artistic holograms is compensated by the fact that individual monochromatic holograms, strange as it may be, reproduce the colour of objects to a certain extent [37]. Most likely this striking effect is the consequence of exact reproduction of the object's microstructure and the experience-gained ability to correlate a certain microstructure with a certain colour.

The process of making artistic holograms is already placed to a large extent to the category of art. In this case very much depends on the choice of the object and the lighting. For example the first and the simplest artistic three-dimensional holograms of a coin were obtained on the very same installation which was employed for the initial experiments and the substantiation of this method [38]. At the remote time of the first experiments on 3-D holography it simply did not occur to the author of the paper mentioned $[2,3]$ to make use of a relief coin as an object. The first large-sized artistic three-dimensional hologram of a complicated object was obtained in (NIKFI) by Dr. G. A. Sobolev in 1967. The studies carried out by those and other groups of investigators have found their reflection mainly as holograms presented at various exhibitions. The number of publications concerning this problem is rather limited (see e.g. [38-41]).

\section{Художественная голография \\ с записью в трехмерной среде при использовании \\ липшмановых фотопластинок}

Обсуждены свойства голографических материалов и технологий, применяемых при трехмерной записи в применении прежде всего для художественных целей. Некоторая доля внимания уделена также механизму взаимодействия лазерного света с материей при различных типах облучения разными лазерами. Упоминаются гакже трудности в технике воспроизведения художественных голограмм.

\section{References}

[1] Gabor D., Proc. Roy. Soc. (London), A197, 454 (1949).

[2] Denisyuk Yu. N., DAN (Academy of Sciences Reports), USSR, 144, No. 6, 1275 (1962).

[3] Denisyuk Yu. N., Optica i Spectr. (Optics and Spectroscopy) XV, 522 (1963).

[4] Denisyuk Yu. N., Protas R. R., Optica i Spectr XIV, 721 (1963).

[5] Lippman G., C. R. Acad. Sci. 112, 274 (1891).

[6] Leith E. N., Upatnieks I., J. Opt. Soc. Am. 54, 1295 (1964).

[7] Valenta E., Die Photographie in natürlichen Farben, Halle 1912.

[8] Zagorskaya Z. A., Optico-mech. Promishlennost (Optical-mechanical Industry) No. 2, 72 (1973).

[9] Andreyeva O. V., Sukhanov V. I., Optica i Spectr. XXX, 786 (1971).

[10] Sukhanov V. I., Andreyeva O. V., Optico-mech. Promishlen. No. 3, 63 (1972).

[11] Protas R. R., Krakau Yu. A., Mikhailova V. I., [in:] Recording Media for Holography (Registriruyushchiye sredi dlya golografii), L., Nauka, p. 41 (1975).

[12] Usanov Yu. E., [in:] Recording Media for Holography, L., Nauka, p. 98 (1975).

[13] Kirillov N. I., Vasilyeva N. V., ZelikmaN V. L., Journal of Scientific and Applied Photography and Cinematography (Zhurnal nauchnoi i prikladnoi fotografii i kinematografii) 15, No. 7, p. 441 (1970).

[14] Kirillov N. I., Vasilyeva N. V., Zelikman V. L., Achievements of Scientific Photography (Uspekhi nauchnoi fotografii) 16, p. 204 (1972).

[15] Kirillov N. I., Vasilyeva N. V., Senchenkov E. P., FeldSHEROV E. M., [in:] Recording Media for Holography, p. 54, Z. Nauka (1975).

[16] Kirillov N. I., [in:] Recording Media for Holography, p. 5, Z. Nauka (1975).

[17] Kirillov M. I., Maslenkova N. G., Vasilyeva N. V., Petrenko A. S., Feldsherov E. M., Gulanyan E. Kh., [in:] The Problem of Holography (Problema Golografii), iss. III, p. 112, Moscow 1973.

[18] Sobolev G. A., Chursin V. N., Serov O. B., [in:] Proceedings of the II-d All-Union Conference on Holography (Materiali II Vsesoyuznoi Konferentsii po golografii) Vol. 1, p. 38, Kiev 1975.

[19] Andreeva O. V., Borin A. V., Gafurova N. S., Mikheev V. P., Prosalova N. A., Sukhanov V. I., [in:] Proceedings of Seminar: Optical Holography and Its Application in Industry (Materiali Seminara: Opticheskaya golografia i yeyo primeneniye $v$ promishlennosti), p. 35, Leningrad 1976.

[20] Yaroslavskaya N. M., [in:] Recording Media for Holography, p. 43, Z. Nauka (1975).

[21] ZagorsKaya Z. A., [in:] Recording Media for Holography, p. 59, L. Nauka (1975).

[22] Yaroslavskaya N. N., Andreyeva O. V., Sukhanov V. I., [in:] Recording Madia for Holography, p. 106, L. Nauka (1975). 
23] Yaroslavskaya N. N., AndReyeva O. V., Sukhanov V. I., Opticomech. Promishl., No. 9, 55 (1975).

[24] Sobolev G. A., Kirillov N. I., Proceeding of the Congress on Photographic Science (Trudi Kongressa po fotograficheskoi nauke) A23, Moscow 1970.

[25] Girina M. G., Sobolev G. A., Rabinovitch Ts. M., Problems of Holography (Problemi Golografii) iss. III, 151, Moscow 1973.

[26] Girina M. G., So bolev G. A., Opt. and Spectrosc. 32, 216 (1972).

[27] Sobolev G. A., Girina M. G., [in:] Recording Media for Holography, p. 88, L. Nauka (1975).

[28] Larionov N. P., Lukin A. V., Mustafin K. S., Problems of Holography, iss. III, p. 90, Moscow 1973.

[29] Andreyeva O. V., Veidenbakh V. A., Levina P. I., SoBOL R. M., Sukhanov V. I., Journal of Scientific and Applied Photography and Cinematography No 1, p. 46 (1975).

[30] Andreyeva O. V., Sukhanov V. I., Optics and Spectrosc. (Optica i Spectr.), XXX, p. 786 (1971).

[31] Lord Rayleigh Phil. Mag. 47, 377 (1899).

[32] Usanov Yu. E. [in:] Recording Media for Holography, p. 98, L. Nauka (1975).

[33] Kovachev M., Sinnov V., Matveeva I., Quantum Electronics 3, No 11, 2399 (1976).

[34] Andreyeva O. V., Sukhanov V. I., Veidenbakh V. A.,
Levina P. I., Sobol K. M., Proceeding of the II-d All-Union Conference on Holography. Vol. 1, p. 76, Kiev 1975.

[35] Varzobova N. D., Staselko D. I., [in:] the Proceedings of Seminar: Optical Holography and its Application in Industry, p. 115, Leningrad 1976.

[36] Zaitseva V. P., Tolchin V. G., Turukhano B. G., Proceeding of the II-d All-Union Conference on Holography, p. 39, Kiev 1975.

[37] Sobolev G. A., Chursin V. N., Serov O. B., Proceedings of the II-d All-Union Conference on Holography, p. 38, Kiev 1975.

[38] Denisyuk Yu. N., Sukhanov V. I., Opt. and Spectrum XXV, 308 (1968).

[39] Denisyuk Yu. N., Zemtsova E. G., Proceedings of the Conference on Implementation of Modern Optics Achievements into the Practical Work of Museums (Materiali konferensii po vnedreniyu $v$ praktiku raboti muzeyev dostizhenii sovremennoi optiki), Sov. Rossiya Pub. House., p. 31, Moscow 1975.

[40] Papoyan S. M., Sobolev G. A., Technika kino i Televidenya (Cine and TV Technique) No. 8, p. 11 (1974).

[41] Vanin V. A., Nazarova L. G., Problems of Holography, iss. 1, p. 53, Moscow 1973.

Received, January 6, 1978. 